\title{
The Demand for Varied Diet with Econometric Models for Count Data
}

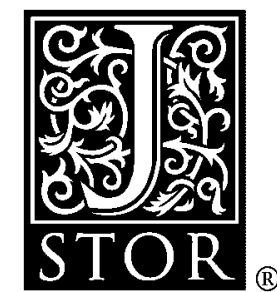

Jonq-Ying Lee

American Journal of Agricultural Economics, Vol. 69, No. 3. (Aug., 1987), pp. 687-692.

Stable URL:

http://links.jstor.org/sici?sici=0002-9092\%28198708\%2969\%3A3\%3C687\%3ATDFVDW\%3E2.0.CO\%3B2-F

American Journal of Agricultural Economics is currently published by American Agricultural Economics Association.

Your use of the JSTOR archive indicates your acceptance of JSTOR's Terms and Conditions of Use, available at

http://www.jstor.org/about/terms.html. JSTOR's Terms and Conditions of Use provides, in part, that unless you have obtained prior permission, you may not download an entire issue of a journal or multiple copies of articles, and you may use content in the JSTOR archive only for your personal, non-commercial use.

Please contact the publisher regarding any further use of this work. Publisher contact information may be obtained at http://www.jstor.org/journals/aaea.html.

Each copy of any part of a JSTOR transmission must contain the same copyright notice that appears on the screen or printed page of such transmission.

The JSTOR Archive is a trusted digital repository providing for long-term preservation and access to leading academic journals and scholarly literature from around the world. The Archive is supported by libraries, scholarly societies, publishers, and foundations. It is an initiative of JSTOR, a not-for-profit organization with a mission to help the scholarly community take advantage of advances in technology. For more information regarding JSTOR, please contact support@jstor.org. 


\title{
The Demand for Varied Diet with Econometric Models for Count Data
}

\author{
Jonq-Ying Lee
}

\begin{abstract}
A negative binomial model was used to study the relationships between food expenditures, household characteristics, and the demand for different food items. The results show that increases in food expenditure increase the number of food items consumed at home, and the number of food items consumed at home is positively related to increases in the number of household members. This change in the number of food items consumed at home increases at a decreasing rate as household size increases and becomes negative when household size becomes large.
\end{abstract}

Key words: demand, food items, negative binomial, Poisson.

The importance of consumer demand for variety in consumption has received increasing attention (Theil and Finke; Jackson; Shonkwiler, Lee, and Taylor; Lee, Shonkwiler, and Brown). It has been noted that as incomes increase consumers tend to increase the number of goods consumed. The studies by Theil and Finke and by Jackson concentrate on broad commodity aggregates. Their results suggest that increases in expenditures on a single broad consumption category are accompanied by increases in the number of individual goods consumed in that category.

Shonkwiler, Lee, and Taylor investigated how the number of individual foods consumed by the household is affected by its preferences and food expenditure. A theoretical model suggested by household production theory (Becker, Lancaster, Deaton and Muellbauer) was adapted to empirical data from a crosssection of households. Results indicated that the number of individual foods consumed responsed strongly to household expenditure on all foods. Lee, Shonkwiler, and Brown used the tobit model to examine the relationship between the number of food items purchased, both in aggregate and in specific food groups, and total food expenditures. Lee, Shonkwiler,

Jonq-Ying Lee is a research economist of the Florida Department of Citrus and an adjunct professor of the Department of Food and Resource Economics, University of Florida.

Florida Agricultural Experiment Station Journal Paper No. 7903.

The author would like to thank two anonymous reviewers for helpful comments. and Brown's results suggest the number of food items consumed at home is responsive to household expenditure on all food.

These four studies used regression methods for continuous variables to estimate the impact of total or food expenditure on the number of food items consumed. This study seeks to measure the household's demand for a varied diet by using discrete regression models to investigate how the number of individual items consumed at home is related to food expenditures and household characteristics.

The following sections review the relevant economic theory about the demand for variety and develop two discrete regression models. Then the relationships between the demand for different food items and food expenditures and household characteristics are estimated with these models

\section{Theoretical Model}

Following Jackson, consider a utility function $u(q)$ defined for any vector of quantities $q$ in some set of $n$ commodities and let

$$
u(q)=u\left(q_{1}, q_{2}, \ldots, q_{n}\right),
$$

where $u(q)$ is to maximized subject to

$$
\begin{aligned}
\Sigma p_{j} q_{j} & =m \text { and } \\
q_{j} & \geqq 0,
\end{aligned}
$$

where $p_{j}$ is the price for $j$ th commodity and $m$ is income. When $u(q)$ is maximized, the following Kuhn-Tucker conditions are satisfied 
(4) $\partial u / \partial q_{j}-\lambda p_{j}=0$, if $j \in S q_{j}>0$, and

(5) $\partial u / \partial q_{j}-\lambda p_{j}<0$, if $j \in \bar{S} q_{j}=0$,

where $\lambda$ is the lagrangian multiplier, $S$ is the set of commodities purchased, and $\bar{S}$ is the set of commodities not purchased, or the complement of $S$. Conditions (2) through (5) can be solved to give the Marshallian demand functions:

$$
q_{j}=g_{j}(p, m),
$$

where $g_{j}(P, m)=0$ if expression (5) holds.

The quantity demanded in (6) is a function of prices and income; therefore, the set of the commodities consumed, i.e., all commodities in $S$ should also be a function of prices and income. This study assumes that consumers allocate their expenditures to broad groups of goods in which food is one of the groups considered; then the food expenditures are allocated to the individual food items. Therefore, the number of food items in set $S$ is a function of food prices and food expenditures. Let $n_{i}$ denote the number of different food items consumed by household $i$. Then $n_{i}$ is a function of food prices and food expenditures, i.e.,

$$
n_{i}=f\left(p_{i}, m_{i}\right)
$$

where $p_{i}$ is a vector of food prices and $m_{i}$ is total food expenditures.

\section{Statistical Model}

In this study count data models are used to examine the impact of household characteristics on the number of different food items consumed by U.S. households. The econometrics related to random counts has been discussed in the biometric literature. (See Patil for a general review.) Recent examples include studies of the number of grocery purchases per period, by Gilbert; the number of patents applied for, by Hausman, Hall, and Griliches; and the number of visits to doctors, by Cameron and Trivedi.

The present study focuses on the number of different food items consumed by households in the United States. Let $y_{i}$ denote the number of different food items consumed by the $i$ th household. It is a random variable, and in a given time interval has a Poisson distribution with the probability density

$$
\text { (8) } \begin{aligned}
\operatorname{Pr}\left(y_{i}=\right. & \left.n_{i}\right) \\
& =e^{-\lambda_{i}} \lambda_{i}^{{ }^{n_{i}}} / n_{i} !, n=0,1,2, \ldots,
\end{aligned}
$$

where $n_{i}$ is the realized value of the random variable. This is a one-parameter distribution with both the mean and variance of $y_{i}$ equal to $\lambda_{i}$. To incorporate a set of explanatory variables $x_{i k}$ into the analysis and to ensure nonnegativity of the mean $y_{i}$, the parameter $\lambda_{i}$ is specified as

$$
\lambda_{i}=\exp \left(x_{i} \beta\right) .
$$

The regression property of this specification arises from $E\left(y_{i}\right)=\lambda_{i}$, but it is not uncommon in empirical analyses to find that $\operatorname{var}\left(y_{i}\right)$ is larger than the mean, which indicates "overdispersion" in the data. ${ }^{1}$ In applied work the Poisson restriction of equal mean and variance should be tested and relaxed if appropriate.

One way to relax this restriction of equal mean and randomness in $\lambda_{i}$ by respecifying (9) as a stochastic equation

$$
\log \lambda_{i}=x_{i} \beta+\epsilon_{i} \text {. }
$$

This results in the so-called compound Poisson distribution. Let $g\left(\epsilon_{i}\right)$ denote the probability density function for $\epsilon_{i}$. If $g\left(\epsilon_{i}\right)$ or equivalently $f\left(\lambda_{i}\right)$ has a gamma distribution, i.e., $\lambda_{i}$ $\sim \operatorname{gamma}\left(\phi_{i}, v_{i}\right)$, then the density function (8) leads to a negative binomial distribution function (Hausman, Hall, and Griliches, p. 922; Cameron and Trivedi, p. 33; Johnson and Kotz, pp. 124-25)

$$
\begin{aligned}
& \operatorname{Pr}\left(y_{i}=n_{i}\right) \\
& =\left(\Gamma\left(y_{i}+v_{i}\right) / \Gamma\left(y_{i}+1\right) \Gamma\left(v_{i}\right)\right)^{*} \\
& \quad\left(v_{i} /\left(v_{i}+\phi_{i}\right)\right)^{v_{i}}\left(\phi_{i} /\left(v_{i}+\phi_{i}\right)\right)^{y_{i}}
\end{aligned}
$$

with $E\left(y_{i}\right)=\phi_{i}$ and $\operatorname{var}\left(y_{i}\right)=\phi_{i}+\phi_{i}{ }^{2} / \nu_{i}$. Since $\phi_{i}>0$ and $\nu_{i}>0$, it is clear that the variance exceeds the mean, so that model allows for overdispersion. The specific parameterization of the resulting form is determined by the parameterization of the gamma distribution. Cameron and Trivedi show that different negative binomial regression models can be generated by linking parameters $\phi_{i}$ and $\nu_{i}$ of the underlying distribution for $\lambda_{i}$ to the explanatory variables $x_{i}$ in different ways. The nonnegative mean $E\left(y_{i}\right)=\exp \left(x_{i} \beta\right)$ is obtained by letting $\phi_{i}=\exp \left(x_{i} \beta\right)$. The variance-mean rela-

\footnotetext{
${ }^{1}$ Note that $\operatorname{var}\left(y_{i}\right)$ could be smaller than the mean; however, the negative binomial model cannot handle this "underdispersion" problem because $\alpha$ is greater than zero by definition.
} 
tionships can be obtained by letting $v_{i}=(1 /$ $\alpha)\left(\exp \left(x_{i} \beta\right)\right)^{k}$ for $\alpha>0$ and arbitrary constant $k$; that is,

$$
\begin{aligned}
& \operatorname{var}\left(y_{i}\right)=\exp \left(x_{i} \beta\right) \\
& \quad \alpha \exp \left((2-k) x_{i} \beta\right)=E\left(y_{i}\right) \\
& +\alpha\left(E\left(y_{i}\right)\right)^{2-k}
\end{aligned}
$$

If $k=1$, then $\operatorname{var}\left(y_{i}\right)=(1+\alpha) E\left(y_{i}\right)$, implying a constant variance-mean ratio (call this model NB I). If $k=0$, then $\operatorname{var}\left(y_{i}\right)=E\left(y_{i}\right)$ $\left(1+\alpha E\left(y_{i}\right)\right)$, so that the variance-mean ratio is linear in the mean (call this model NB II). Clearly there are other possibilities as well. The two models imply different assumptions about the functional form of heteroskedasticity, and hence, in general, will lead to different estimates of $\beta$. Other choices of the probability density function for $\epsilon_{i}$, such as the standard normal density, the uniform distribution, etc. are discussed in Johnson and Kotz (pp. 183215). The resulting compound Poisson might not have a closed form and, hence, could be computationally cumbersome.

The parameters $\beta$ specified in (8) and (9) can be estimated by a scoring method (Maddala, pp. 51-53); the parameters in (11) and (12) can be estimated with the quasi-generalized pseudo maximum-likelihood (QGPML) method developed by Gourieroux, Monfort, and Tragnon $1984 \mathrm{a}, \mathrm{b}^{2}$ In this study a scoring test is used to test for an overdispersion problem (Cameron and Trivedi, p. 41); that is, the Poisson model is tested against the alternative that the distribution belongs to the negative binomial distribution. The test statistic under $\mathrm{H}_{\mathrm{o}}$ is

$$
\begin{aligned}
T_{L}=(N)^{1 / 2} \Sigma \hat{\mu}_{i}^{k-1} C_{i} / \\
\\
\quad\left(\left(\Sigma C_{i}^{2}\right)^{1 / 2}\left(\Sigma\left(\hat{\mu}_{i}^{k-1}\right)^{2}\right)^{1 / 2}\right),
\end{aligned}
$$

where $\hat{\mu}_{i}=\exp \left(x_{i} \hat{\beta}\right), C_{i}=\left(\left(n_{i}-\hat{\mu}_{i}\right)^{2}-n_{i}\right) /$ $\hat{\mu}_{i}, T_{L}$ has an asymptotic $t$ distribution, and $N$ is the number of observations in the data set. If $k=1$, then the alternative distribution is NB I; if $k=2$, then the alternative distribution is NB II.

This test is useful in rejecting the maintained model, i.e., Poisson distribution, but is less helpful in providing the information for a better class of models. Therefore, if the test

\footnotetext{
${ }^{2}$ The likelihood functions for Poisson and negative binomial models are presented in Gourieroux et al. (pp. 705-6).
}

results show that the negative binomial model is preferred, it too should be tested against other more flexible alternatives. However, this study does not consider such models.

\section{Data and Variables}

The U.S. Department of Agriculture's 197778 Nationwide Food Consumption Survey (NFCS) is the source of data used for the statistical analysis. Approximately 15,000 households from the 48 contiguous states were surveyed during 1 April 1977 through 31 March 1978. The NFCS public tapes contain detailed information on household food consumption and expenditures.

The dependent variable is the number of different food items consumed during the survey week. The household characteristics chosen for the study include the number of household members in twelve age-sex categories, household size-squared, total food expenditure in dollars during the survey week, the at-home food expenditure share, and dummy variables for region, session, urbanization, race, presence and employment status of the male and female household heads, and participation in food stamp programs. Descriptive statistics for these variables are given in table 1 . The dependent variables listed above do not include price variables because of the difficulty of estimating a price index for each household in the sample. Accordingly, relationship (7) can be written as

$$
n_{i}=f\left(h c_{i}, m_{i}\right),
$$

where $h c_{i}$ is the set of household characteristics shown in table 1 .

A fifteen-digit code system is used by the NFCS to identify different food items. Each food item can be reclassified into a broader category by using the truncated food code. For example, if the fifteen-digit food codes are used, plain corn flakes, presweetened corn flakes, and $40 \%$ bran flakes are different food items. When the first five digits of the food codes are used, the two corn flake products will have the same food code, while corn flake products and bran flakes will have different food codes. In this study, food items are defined by the first five digits of the fifteendigit food codes used by the NFCS. The possible range of $n_{i}$ is from 1 to 153 . 
Table 1. Sample Means, Proportions, and Standard Errors for Household Characteristic Variables

\begin{tabular}{|c|c|c|}
\hline Variable & Mean & $\begin{array}{c}\text { Standard } \\
\text { Error }\end{array}$ \\
\hline Household food expenditure $(\$ / w k)^{a}$ & 52.2199 & 33.8515 \\
\hline Food items (number) & 46.6865 & 18.5685 \\
\hline Household size (persons) & 2.9542 & 1.6637 \\
\hline$M \leqq 3^{\mathrm{b}}$ & 0.0870 & 0.3092 \\
\hline$F \leqq 3^{b}$ & 0.0826 & 0.2989 \\
\hline $10 \geqq M \geqq 4$ & 0.1771 & 0.4641 \\
\hline $10 \geqq F \geqq 4$ & 0.1756 & 0.4639 \\
\hline $15 \geqq M \geqq 11$ & 0.1202 & 0.3734 \\
\hline $15 \geqq F \geqq 11$ & 0.1181 & 0.3702 \\
\hline $25 \geqq M \geqq 16$ & 0.2883 & 0.5951 \\
\hline $25 \geqq F \geqq 16$ & 0.3048 & 0.5759 \\
\hline $50 \geqq M \geqq 26$ & 0.4175 & 0.5086 \\
\hline $50 \geqq F \geqq 26$ & 0.4692 & 0.5113 \\
\hline$M>50$ & 0.3175 & 0.4754 \\
\hline$F>50$ & 0.3963 & 0.5279 \\
\hline \multicolumn{3}{|l|}{ Proportions: } \\
\hline Food Stamp participation & 0.0677 & 0.2513 \\
\hline Race (white) & 0.8530 & 0.3541 \\
\hline High school $(F)^{\mathrm{c}}$ & 0.5037 & 0.5000 \\
\hline College education $(F)^{\mathrm{c}}$ & 0.2728 & 0.4454 \\
\hline Winter ${ }^{d}$ & 0.2727 & 0.4454 \\
\hline Spring $^{\mathrm{d}}$ & 0.2227 & 0.4160 \\
\hline Summer ${ }^{d}$ & 0.2318 & 0.4220 \\
\hline Central city ${ }^{\mathrm{e}}$ & 0.2961 & 0.4565 \\
\hline Suburban ${ }^{\mathrm{e}}$ & 0.3507 & 0.4772 \\
\hline Northeast $\mathrm{f}^{\mathrm{f}}$ & 0.2373 & 0.4254 \\
\hline North central ${ }^{\mathrm{f}}$ & 0.2510 & 0.4336 \\
\hline South ${ }^{\mathrm{f}}$ & 0.3475 & 0.4762 \\
\hline Male head (present) ${ }^{\mathrm{g}}$ & 0.7636 & 0.4249 \\
\hline Female head (present) ${ }^{g}$ & 0.9222 & 0.2679 \\
\hline Male employment ${ }^{\mathrm{h}}$ & 0.5634 & 0.4960 \\
\hline Female employment ${ }^{\text {h }}$ & 0.3713 & 0.4832 \\
\hline At-home food exp. share & 0.9023 & 0.1647 \\
\hline
\end{tabular}

a Include at-home and away-from-home food expenditures.

${ }^{b}$ Represents the number of males $(M)$ or females $(F)$ present in the household of age less than or equal to three years old. Same notations were used for other sex-age groups.

${ }^{c}$ Female head education. High school $(F)$ equals one if female head had high school education, otherwise equals zero. College education $(F)$ equals one if female head had college education, otherwise equals zero. Primary school education was used as the base for comparison.

d Fall season was used as the base for comparison.

' Rural residence was used as the base for comparison.

${ }^{f}$ The western United States was used as the base for comparison.

${ }^{8}$ Male head equals one if there was a male head in the household, otherwise equals zero. Similar definition was used to define female head variable.

${ }^{\mathrm{h}}$ Male employment equals one if male head was employed, otherwise equals zero. Similar definition was used for female employment variable.

\section{Results}

The first column of table 2 presents the corresponding estimates of an OLS regression of (10). The Poisson estimates are shown in column (2). Poisson results are similar to OLS; however, the estimated standard errors of the Poisson estimates are at least two times smaller. This result is similar to that found in Hausman, Hall, and Griliches.

The estimated Poisson model was used to apply the score test [equation (13)] of the null hypothesis of Poisson versus the alternatives of two negative binomial models. The estimated $T_{L}$ statistics were 46.11 and 48.56 for NB I and NB II, respectively, which strongly rejects the Poisson. In addition, the Poisson estimates were used to estimate the following regressions:

$$
\begin{aligned}
\operatorname{vâr}\left(n_{i}\right)= & 5.0221 \hat{\lambda}_{i}, \text { and } \\
& (.1347) \\
\operatorname{vâr}\left(n_{i}\right) / \hat{\lambda}_{i}= & .7466+.0582 \lambda_{i}, \\
(.1692) & (.0035)
\end{aligned}
$$

where $\hat{E}\left(n_{i}\right)=\hat{\lambda}_{i}, \operatorname{vâr}\left(n_{i}\right)=\left(n_{i}-\hat{\lambda_{i}}\right)^{2}$, and the numbers in parentheses are standard errors. Equation (15) again confirms that the negative binomial is preferred to the Poisson, and (16) suggests that NB II is preferred to NB I. The last column in table 2 show the QGPML estimates for the NB II model.

The OLS and Poisson point estimates are similar to those in the NB II model; however, the estimated variances under the OLS assumption are smaller than those for the NB II model, and the estimated variances under the Poisson assumption are substantially smaller, reflecting the consequences of imposing the restriction of equality of mean and variance on the model. Results from the NB II model will be used in the following discussion.

The parameter estimates in table 2 indicate how the explanatory variables affect the expected value of the number of different food items consumed at home by U.S. households. Note that

$$
\partial E\left(n_{i}\right) / \partial x_{i k}=\beta_{k} \exp \left(x_{i} \beta\right) .
$$

Hence the parameter estimates should be interpreted as the impacts of the $k$ th-independent variable on the number of food items consumed at home. The signs of the parameter estimates indicate the directions of the impacts. Based on the asymptotic $t$-ratios, all the parameter estimates are significantly different from zero at $\alpha=.10$ level except the estimates for food stamp participation, winter, summer, urbanization, northeastern region, north central region, and male employment status dummy variables. The signs of the parameter estimates are largely consistent with expectations.

All parameter estimates for age-sex composition variables are positive and significant. The effect of the addition of a given household 
Table 2. Estimates for Parameters of the Food Consumption Equations

\begin{tabular}{|c|c|c|c|}
\hline \multirow[b]{2}{*}{ Variable } & \multicolumn{3}{|c|}{ Estimates } \\
\hline & $\mathrm{OLS}^{\mathbf{a}}$ & Poisson & NB II \\
\hline Intercept & $\begin{array}{c}2.0370 \\
(0.0262)^{\mathrm{b}}\end{array}$ & $\begin{array}{c}2.2943 \\
(0.0123)\end{array}$ & $\begin{array}{r}2.2061 \\
(0.0676)\end{array}$ \\
\hline \multicolumn{4}{|l|}{ Household composition: } \\
\hline$M \leqq 3$ & $\begin{array}{c}0.1408 \\
(0.0069)\end{array}$ & $\begin{array}{c}0.1126 \\
(0.0035)\end{array}$ & $\begin{array}{c}0.0880 \\
(0.0203)\end{array}$ \\
\hline$F \leqq 3$ & $\begin{array}{c}0.1780 \\
(0.0071)\end{array}$ & $\begin{array}{c}0.1298 \\
(0.0035)\end{array}$ & $\begin{array}{c}0.1100 \\
(0.0211)\end{array}$ \\
\hline $10 \geqq M \geqq 4$ & $\begin{array}{c}0.1378 \\
(0.0101)\end{array}$ & $\begin{array}{c}0.1188 \\
(0.0049)\end{array}$ & $\begin{array}{c}0.0918 \\
(0.0288)\end{array}$ \\
\hline $10 \geqq F \geqq 4$ & $\begin{array}{c}0.2022 \\
(0.0093)\end{array}$ & $\begin{array}{c}0.1575 \\
(0.0045)\end{array}$ & $\begin{array}{l}0.1346 \\
(0.0266)\end{array}$ \\
\hline $15 \geqq M \geqq 11$ & $\begin{array}{c}0.0951 \\
(0.0116)\end{array}$ & $\begin{array}{c}0.1282 \\
(0.0055)\end{array}$ & $\begin{array}{c}0.0979 \\
(0.0320)\end{array}$ \\
\hline $15 \geqq F \geqq 11$ & $\begin{array}{c}0.2564 \\
(0.0104)\end{array}$ & $\begin{array}{c}0.1769 \\
(0.0498)\end{array}$ & $\begin{array}{l}0.1656 \\
(0.0293)\end{array}$ \\
\hline $25 \geqq M \geqq 16$ & $\begin{array}{c}0.2012 \\
(0.0092)\end{array}$ & $\begin{array}{c}0.1722 \\
(0.0046)\end{array}$ & $\begin{array}{l}0.1594 \\
(0.0281)\end{array}$ \\
\hline $25 \geqq F \geqq 16$ & $\begin{array}{c}0.2146 \\
(0.0092)\end{array}$ & $\begin{array}{c}0.1688 \\
(0.0047)\end{array}$ & $\begin{array}{c}0.1574 \\
(0.0289)\end{array}$ \\
\hline $50 \geqq M \geqq 26$ & $\begin{array}{c}0.1150 \\
(0.0073)\end{array}$ & $\begin{array}{c}0.1212 \\
(0.0038)\end{array}$ & $\begin{array}{l}0.1053 \\
(0.0225)\end{array}$ \\
\hline $50 \geqq F \geqq 26$ & $\begin{array}{c}0.1428 \\
(0.0075)\end{array}$ & $\begin{array}{c}0.1331 \\
(0.0038)\end{array}$ & $\begin{array}{c}0.1166 \\
(0.0225)\end{array}$ \\
\hline$M>50$ & $\begin{array}{c}0.1677 \\
(0.0082)\end{array}$ & $\begin{array}{c}0.1279 \\
(0.0043)\end{array}$ & $\begin{array}{l}0.1058 \\
(0.0264)\end{array}$ \\
\hline$F>50$ & $\begin{array}{c}0.1694 \\
(0.0081)\end{array}$ & $\begin{array}{r}0.1379 \\
(0.0043)\end{array}$ & $\begin{array}{l}0.1176 \\
(0.0263)\end{array}$ \\
\hline (Household size) $)^{2}$ & $\begin{array}{c}-0.0183 \\
(0.0006)\end{array}$ & $\begin{array}{c}-0.0127 \\
(0.0003)\end{array}$ & $\begin{array}{r}-0.0121 \\
(0.0018)\end{array}$ \\
\hline \multicolumn{4}{|l|}{ Household characteristics: } \\
\hline Food Stamp participation & $\begin{array}{l}-.0002 \\
(0.0101)\end{array}$ & $\begin{array}{c}0.0068 \\
(0.0055)\end{array}$ & $\begin{array}{c}0.0051 \\
(0.0312)\end{array}$ \\
\hline Race (white) & $\begin{array}{c}0.0823 \\
(0.0073)\end{array}$ & $\begin{array}{c}0.0846 \\
(0.0039)\end{array}$ & $\begin{array}{c}0.0780 \\
(0.0220)\end{array}$ \\
\hline High school $(F)$ & $\begin{array}{c}0.1025 \\
(0.0078)\end{array}$ & $\begin{array}{r}0.1036 \\
(0.0040)\end{array}$ & $\begin{array}{c}0.0930 \\
(0.0223)\end{array}$ \\
\hline College education $(F)$ & $\begin{array}{c}0.1642 \\
(0.0090)\end{array}$ & $\begin{array}{c}0.1858 \\
(0.0044)\end{array}$ & $\begin{array}{l}0.1765 \\
(0.0251)\end{array}$ \\
\hline Winter & $\begin{array}{l}-.0131 \\
(0.0068)\end{array}$ & $\begin{array}{c}0.0032 \\
(0.0032)\end{array}$ & $\begin{array}{c}0.0009 \\
(0.0190)\end{array}$ \\
\hline Spring & $\begin{array}{c}-0.0317 \\
(0.0071)\end{array}$ & $\begin{array}{c}-0.0283 \\
(0.0034)\end{array}$ & $\begin{array}{r}-0.0264 \\
(0.0200)\end{array}$ \\
\hline Summer & $\begin{array}{c}-0.0348 \\
(0.0071)\end{array}$ & $\begin{array}{c}-0.0260 \\
(0.0034)\end{array}$ & $\begin{array}{r}-0.0237 \\
(0.0198)\end{array}$ \\
\hline Central city & 0.0362 & $\begin{array}{l}0.0074 \\
(0.0032)\end{array}$ & $\begin{array}{r}0.0070 \\
(0.0186)\end{array}$ \\
\hline Suburban & $\begin{array}{c}0.0470 \\
(0.0061)\end{array}$ & $\begin{array}{c}0.0207 \\
(0.0029)\end{array}$ & $\begin{array}{c}0.0171 \\
(0.0172)\end{array}$ \\
\hline Northeast & $\begin{array}{l}-.0151 \\
(0.0083)\end{array}$ & $\begin{array}{c}0.0099 \\
(0.0038)\end{array}$ & $\begin{array}{c}0.0028 \\
(0.0226)\end{array}$ \\
\hline North central & $\begin{array}{c}0.0141 \\
(0.0081)\end{array}$ & $\begin{array}{c}0.0414 \\
(0.0038)\end{array}$ & $\begin{array}{c}0.0081 \\
(0.0225)\end{array}$ \\
\hline South & $\begin{array}{c}-0.0753 \\
(0.0078)\end{array}$ & $\begin{array}{c}-0.0704 \\
(0.0037)\end{array}$ & $\begin{array}{r}-0.0741 \\
(0.0216)\end{array}$ \\
\hline Total food expenditure & $\begin{array}{c}0.0071 \\
(0.0001)\end{array}$ & $\begin{array}{c}0.0053 \\
(0.0000)\end{array}$ & $\begin{array}{c}0.0074 \\
(0.0003)\end{array}$ \\
\hline At-home food exp. share & $\begin{array}{c}0.6684 \\
(0.0188)\end{array}$ & $\begin{array}{c}0.6126 \\
(0.0085)\end{array}$ & $\begin{array}{c}0.6742 \\
(0.0486)\end{array}$ \\
\hline Male head & $\begin{array}{c}0.1167 \\
(0.0123)\end{array}$ & $\begin{array}{c}0.0913 \\
(0.0059)\end{array}$ & $\begin{array}{l}0.0935 \\
(0.0338)\end{array}$ \\
\hline Female head & $\begin{array}{c}0.2139 \\
(0.0157)\end{array}$ & $\begin{array}{c}0.1923 \\
(0.0077)\end{array}$ & $\begin{array}{r}0.1924 \\
(0.0402)\end{array}$ \\
\hline Male employment & $\begin{array}{c}0.0378 \\
(0.0076)\end{array}$ & $\begin{array}{c}0.0333 \\
(0.0036)\end{array}$ & $\begin{array}{c}0.0245 \\
(0.0209)\end{array}$ \\
\hline Female employment & $\begin{array}{c}-0.0432 \\
(0.0057)\end{array}$ & $\begin{array}{r}-0.0287 \\
(0.0027)\end{array}$ & $\begin{array}{r}-0.0303 \\
(0.0162)\end{array}$ \\
\hline$\hat{\alpha}$ & & & $\begin{array}{r}0.7080 \\
(0.0024)\end{array}$ \\
\hline
\end{tabular}

It is found that $\hat{\boldsymbol{\epsilon}}_{i}{ }^{2}$ is a function of total food expenditure (TFE) and household size $(H Z)$, i.e.,

$$
\hat{\epsilon}_{i}^{2}=\underset{(.0063)}{.1569}+\underset{(.0001)}{.0003} T F E_{i}-\underset{(.0022)}{.0225} H Z_{i}+e_{i} ;
$$

therefore, a GLS procedure (Judge et al., pp. 136-37) was used to correct for heteroscedasticity.

${ }^{b}$ Numbers in parentheses are standard errors of estimates. member, regardless of sex, increases with age, reaching a peak for members of age between sixteen and twenty-five, then decreases slowly. Moreover, the addition of given female members has a greater impact on the number of different food items consumed at home than does the addition of a male member of the same age group. The parameter estimate for the household-size-square variable suggests economies of scale associated with the number of food items consumed at home.

Since the coefficient for household size is negative, additions of household members increase household size and reduce the positive impact of household members on the number of food items consumed at home. For example, the positive impact of the arrival of a male infant to a four-person household would be offset by the negative impact of increased household size on the number of different food items consumed at home. In addition, for household size larger than seven persons, the estimates show that any addition of household members would actually decrease the number of different food items consumed at home.

The results show that food stamp program participation has no appreciable effect on the number of food items consumed at home. White households tend to consume a greater number of different food items at home than do those of other races. The parameter estimates for female head education show that if the female head has a college education the number of food items consumed at home is larger than in those households where female heads have only a primary or high school education. In addition, if the female head has a high school education, the number of food items consumed at home is larger than in those households where female heads have only primary school education.

The parameter estimates for seasonal dummy variables indicate different patterns of seasonal variation in the number of food items consumed at home. The number of food items consumed at home is lowest in spring and highest in winter and fall.

One reason for using location dummy variables is to account for systematic price differences among locations. The results show that whether the household is located in central city, suburb, or rural area makes no difference in the number of different food items consumed at home. However, if the household is located in the southern region, then the number of different food items consumed at home are smaller than in other regions. 
The results also indicate that the number of food items consumed at home increases when food expenditure increases. In addition, as the at-home food expenditure share increases, the number of food items consumed at home also increases. Finally, the presence of a female head in the household contributes to a larger number of food items consumed at home than the presence of a male head. However, if the female head is employed outside of the household, her contribution to the number of food items consumed at home would decline slightly.

\section{Concluding Comments}

This study suggests that increases in household food expenditures increase the number of different food items consumed at home, a result consistent with the results of Theil and Finke; Jackson; Shonkwiler, Lee, and Taylor; and Lee, Shonkwiler, and Brown. In addition, this study shows that the number of food items consumed at home is positively related to increases in the number of household members. This change in the number of food items consumed at home increases at a decreasing rate as household size increases and becomes negative when household size becomes large.

For its methodological contribution, this study demonstrates that using the OLS regression method for continuous variables may underestimate the standard errors of the parameter estimates. In addition, imposing the equality of the conditional mean and variance as a result of using the Poisson model also underestimates the standard errors of the parameter estimates when overdispersion is a problem. The NB II model adopted in this study allows greater flexibility for modeling the relationship between the mean and variance, but more work is needed to explore other more flexible alternatives.

[Received August 1986; final revision received January 1987.]

\section{References}

Becker, G. "A Theory of the Allocation of Time." Econ. J. 75(1965):493-517.

Cameron, A. C., and P. K. Trivedi. "Econometric Models Based on Count Data: Comparisons and Applications of Some Estimators and Tests." J. Appl. Econometrics 1(1986):29-53.

Deaton, A., and J. Muellbauer. Economics and Consumer Behavior. Cambridge: Cambridge University Press, 1980.

Gilbert, C. L. "Econometric Models for Discrete Economic Processes." University of Oxford Disc. Pap. presented at the Econometric Society European meeting, Athens, 1979.

Gourieroux, C., A. Monfort, and A. Trognon. "Pseudo Maximum Likelihood Methods: Applications to Poisson Models.' Econometrica 52(1984a):701-20.

" "Pseudo Maximum Likelihood Methods: Theory." Econometrica 52(1984b): 681-700.

Hausman, J., B. H. Hall, and Z. Griliches. "Econometric Models for Count Data with an Application to the Patents-R\&D Relationship." Econometrica 52 (1984):909-38.

Jackson, L. F. "Hierarchic Demand and the Engel Curve for Variety." Rev. Econ. and Statist. 66(1984):8 15.

Johnson, N. L., and S. Kotz. Discrete Distributions. New York: John Wiley \& Sons, 1972.

Judge, G. G., W. E. Griffiths, R. C. Hill, and T-C Lee. The Theory and Practice of Econometrics. New York: John Wiley \& Sons, 1980.

Lancaster, K. J. "A New Approach to Consumer Theory." J. Polit. Econ. 74(1966):132-57.

Lee, J., J. S. Shonkwiler, and M. G. Brown. "Some Evidence of the Demand for Variety-A Case Study of Food Items." Paper presented at AAEA annual meeting, Iowa State University, Ames, 1985.

Maddala, G. S. Limited-Dependent and Qualitative Variables in Econometrics. New York: Cambridge University Press, 1983.

Patil, G. P. Random Counts in Models and Structures: volume 1. University Park: Pennsylvania State University Press, 1970.

Shonkwiler, J. S., J. Lee, and T. G. Taylor. "The Significance of a Varied Diet: A Household Production Function Approach."' Paper presented at AAEA annual meeting, Iowa State University, Ames, 1985.

Theil, H., and R. Finke. "The Consumer's Demand for Diversity." Eur. Econ. Rev. 23(1983):348-59. 